\title{
Llorar tras el parto: el primer sermón del predicador real Jerónimo de Florencia a las honras de la reina Margarita
}

\section{Crying after childbirth: first sermon of the Royal Preacher Jerónimo de Florencia to the funeral honors of Queen Margarita}

\author{
JAUME GARAU \\ Universidad de las Islas Baleares \\ Instituto de Estudios Hispánicos en la Modernidad (IEHM): Unidad Asociada al CSIC \\ jgarau@uib.es
}

Resumen: El predicador real Jerónimo de Florencia (1565-1633) predicó dos sermones de honras: el 18 de noviembre de 1611 en San Jerónimo el Real y, en Santa María, el 19 de diciembre del mismo año. En ellos glosa la figura de la reina Margarita, muerta de sobreparto. En estos sermones, Margarita de Austria aparece presentada bajo lo que podríamos denominar la "verdad oficial", como es propio de unos textos de esta naturaleza y en los que se anuncia como un ser sacralizado: al punto de ser una dulce compañía para el rey, una amorosa madre para sus hijos, una piadosa reina para sus vasallos y, como rasgo no menos importante, una firme columna de la Iglesia, entre otros aspectos que resalta este importante predicador real desde su privilegiada atalaya del poder. En este artículo estudiamos el primero de estos sermones.

Palabras clave: Jerónimo de Florencia, Margarita de Austria, sermón funeral.

\begin{abstract}
The Royal Preacher Jerónimo de Florencia (1565-1633) delivered two sermons as part of the funeral honors celebrating the decease of the Queen, the first one in San Jerónimo el Real on November 18th, 1611, and the second one in Santa María on December 19th, in the same year. In both of them, the figure of Queen Margarita, who died during the confinement, is glossed over. In these sermons, Margarita de Austria is presented through what it could called the "official truth", as is appropriate in texts of this kind of nature. She is lauded as a sacred being: to such an extent that she is presented as sweet company for the King; as a loving mother to her children; as a pious queen for her lieges and, last but not least, as a solid pillar of the Church, among other aspects highlighted by this important royal preacher from his privileged vantage point of power. In this article we study the first of these sermons.
\end{abstract}

Keywords: Jerónimo de Florencia, Margarita de Austria, Funeral Sermon.

Recibido: 29 de diciembre de 2018; aceptado: 2 de diciembre de 2019; publicado: 31 de marzo de 2020. Revista Historia Autónoma, 16 (2020), pp. 37-51

e-ISSN: 2254-8726; https://doi.org/10.15366/rha2020.16.002 
De entre los distintos géneros de nuestro Siglo de Oro, el de la oratoria sagrada sigue siendo el menos estudiado pese a que en los últimos tiempos se han incrementado las aportaciones que abordan este género", que no dudamos en calificar como "el más popular" de aquel importantísimo período de nuestra letras y, sin duda, una de las claves esenciales de la cultura de la época, en la medida en que el sermón es virtualmente susceptible de ser estudiado desde diferentes perspectivas: como documento costumbrista, como reflejo de las manifestaciones de la vida social y religiosa o, y no menos importante, como una muestra de la ideología dominante ${ }^{2}$. Todo ello sin olvidar su pertenencia a la literatura oral y, sin dejar de tener en cuenta, en los grandes predicadores del momento, la alta calidad de su estilo y su adscripción a las principales corrientes estilísticas del siglo.

De entre los distintos predicadores destacan, por su relevancia política y social, los del rey como, cada vez más, nos va desvelando Fernando Negredo en sus contribuciones en las que aborda esta importante figura de la España de los Austrias ${ }^{3}$.

En la relación de predicadores de nuestro Siglo de Oro, el jesuita Jerónimo de Florencia (1565-1633) ocupa un lugar destacado, especialmente por cuanto en su figura y obra oratorias se conjugan en su grado máximo las relaciones entre el poder y el púlpito. Florencia predicó durante buena parte del reinado del Rey Piadoso y parte del de su sucesor, Felipe IV ${ }^{4}$. Su obra oratoria hay que enmarcarla, por tanto, y siguiendo a Miguel Herrero García ${ }^{5}$, en la denominada "Edad de Oro" o "Época segunda", aquella que comprende los primeros años del reinado de

\footnotetext{
${ }^{1}$ Es obligado resaltar entre la bibliografía más destacada los diversos estudios de Cerdan, Francis, entre los que destacamos, "Actualidad de los estudios sobre oratoria sagrada del Siglo de Oro (1985-2002). Balance y perspectivas", en Criticón, 84-85 (2002), pp. 9-42, con abundante bibliografía actualizada a la fecha y diversas contribuciones.

${ }^{2}$ Cfr. Cerdan, Francis, "La oratoria sagrada del siglo xvir: un espejo de la sociedad", en García de Enterría, María Cruz y Alicia Cordón Mesa (eds.): Actas del IV Congreso Internacional de la Asociación Internacional Siglo de Oro (AISO) (Alcalá de Henares, 22-27 de julio de 1996), vol. 1, Alcalá de Henares, Universidad de Alcalá de Henares, 1998, pp. 23-44.

${ }^{3}$ Especialmente en Negredo, Fernando, Los predicadores de Felipe IV. Corte, intrigas y religión en la España del Siglo de Oro, Madrid, Actas, 2006.

${ }^{4}$ Sobre la predicación de los jesuitas en general, puede verse, de Herrero Salgado, Félix, La oratoria sagrada en los siglos XVI y XVII. La predicación de la Compañía de Jesús, Madrid, FUE, 2001 y, singularmente en el caso de Jerónimo de Florencia el capítulo VIII (pp. 441-472). También de Garau, Jaume, "Jerónimo de Florencia (15651633), predicador real", en Actas del VII Congreso de la AISO (2005), Madrid, AISO, 2006a, pp. 275-280. https:// doi.org/10.31819/9783964565587-036; "Notas para una biografía del predicador real Jerónimo de Florencia (15651633)", en Revista de Literatura, 135 (2006b), pp. 101-122. https://doi.org/10.3989/revliteratura.2006.v68.i135.4; y "Jerónimo de Florencia y su sermón a las honras fúnebres de Felipe III", en Méridiennes. Homenaje a Francis Cerdan, 2007, pp. 323-337. De José Servera es importante tener en cuenta su estudio "Jerónimo de Florencia, predicador de honras: Sermón a las honras de la emperatriz doña María", en Actas del VII Congreso de la AISO (2005), Madrid, AISO, pp. 563-568. https://doi.org/10.31819/9783964565587-080; y de Voinier, Sarah, "Défense et censure d'un jésuite de cour: la controverse autor du Père Jerónimo de Florencia", en Atlante. Revue d'études romanes, 2 (2015), pp. 191-210. En relación a su influencia en la política de su tiempo, son imprescindibles las páginas que le dedica Julián Lozano Navarro en "3.4. El padre Jerónimo de Florencia en la escena política" y “4.3 ¿Una oficina de negocios jesuítica en la Corte de la Monarquía? La labor de los padres Florencia, Salazar, Albornoz y Pimentel”, en La Compañía de Jesús y el poder en la España de los Austrias, Madrid, Cátedra, 2005, pp. 147-156 y 199-215, respectivamente. Véase también Alvar, Alfredo, Felipe IV. El Grande, Madrid, La Esfera de los Libros, 2018, pp. 113-118.

${ }^{5}$ Herrero García, Miguel, Sermonario clásico, Madrid-Buenos Aires, Escelicer, 1942.
} 
Felipe III hasta la fecha de 1612, que es cuando aparece en el púlpito fray Hortensio Félix Paravicino, y hasta la muerte de ambos predicadores en 1633.

Famoso por la predicación de las honras fúnebres de personajes ilustres de la época, Florencia fue amigo de grandes de la nobleza y de personajes importantes de la iglesia madrileña, como el trinitario Simón de Rojas, ahora santo ${ }^{6}$. Al parecer, entre sus enemigos se contaban escritores tan destacados como Luis de Góngora quien, en una carta conservada, le achaca el haber negado la asistencia espiritual a su amigo don Rodrigo Calderón, antes de ser ajusticiado en la Plaza Mayor de Madrid en 16217, y se le atribuye un soneto en el que don Luis le censura su vanidad y afición desmesurada a la vida regalada de la Corte ${ }^{8}$.

Florencia fue considerado, ya en su tiempo, sujeto de singular estimación. Así, un predicador de la talla de Hernando de Santiago le denominaba "predicador de reyes y rey de predicadores", y para un eminente compañero de orden como fue Baltasar Gracián era tenido por "Ambrosio de este siglo", tal como le califica en su Agudeza y arte de ingenio ${ }^{10}$, entre otras opiniones de ingenios de su tiempo, de muy variado signo. Debemos recordar, en tanto que dato que redunda en la aceptación de sus sermones, estimados como modélicos en su siglo, que su nombre es uno de los que figuran en la relación de autores elegidos por la Real Academia para el llamado Diccionario de Autoridades.

La historia de su vida corrió a la sombra de la Corte por espacio de casi 33 años. Este hecho le proporcionó una atalaya de primer orden desde la que fue testigo privilegiado de sus acontecimientos más destacados al punto de influir decisivamente en la caída del duque de Lerma en la privanza. Según refiere Julián J. Lozano, haciéndose eco de los trabajos de Magdalena Sánchez:

Florencia, en estos momentos [es] el hombre clave de la Compañía en la
Corte, sigue trabajando más para eliminar a Lerma que para aupar a su hijo.
El vehículo que utiliza para ello es su reconocida habilidad retórica. De hecho,
sus palabras en el púlpito hacen tanta mella en el rey viudo que Felipe III llega
a afirmar que uno de sus sermones, predicado en 1618 , le inspiró la idea de
prescindir del duque de Lerma. Este, caído ya en desgracia intenta aplazar su
salida de la Corte buscando la mediación del padre Florencia, lo cual es una
prueba palpable del poder del jesuita junto al rey ${ }^{11}$.

La estrecha relación que mantuvo con Felipe III atestigua esta vinculación al poder, tanto que llegó a convertirse en su confidente, ayudarle a bien morir, gracias a sus eficaces consuelos

\footnotetext{
${ }^{6}$ Aliaga Asensio, Pedro, "Simón de Rojas, trinitario", en Testimonios y testigos, 233 (2003), pp. 1-16.

${ }^{7}$ Góngora y Argote, Luis de, Obras completas, edición de Juan e Isabel Millé y Giménez, Madrid, Aguilar, 1972, pp. 993-994.

${ }^{8}$ Ibídem, pp. 550-551.

9 "Dedicatoria", en Sermón que predicó..., Granada, 1621. Baltasar Gracián reproduce esta expresión en su obra Agudeza y arte de ingenio.

${ }^{10}$ Gracián, Baltasar, Agudeza y arte de Ingenio, II, edición de Evaristo Correa Calderón, Madrid, Castalia, 1969 , p. 184. Otras referencias en este mismo tomo: p. 191 y en I: pp. 110, 226.

${ }^{11}$ Lozano Navarro, Julián J., La Compañía de Jesús y el poder... op. cit., pp. 154-155.
} 
en el momento final, e influir, según rumor ampliamente extendido, en la redacción de las mandas de su testamento.

Tras la muerte del Piadoso, apoyó al nuevo gobierno del conde-duque de Olivares y mantuvo su situación privilegiada al ser nombrado confesor de los infantes don Carlos y don Fernando, al tiempo que formó parte destacada de la famosa Junta de Reformación, entre otras ${ }^{12}$.

Su predicación descuella en el difícil arte de las honras fúnebres. No en vano así las calificaba el mercedario fray Francisco Antonio de Isasi y Guzmán, predicador de S. M., al afirmar que "predicar honras no sólo suele ser prueba de las tareas estudiosas, sino piedra de toque de los predicadores; mar en que han hallado muchos bajíos los más apreciables vasos"13.

Predicar honras conllevaba, pues, muchos peligros ya que, al presentar lo que ahora llamaríamos "una verdad oficial" del personaje en cuestión, especialmente en el caso de figuras de la realeza como la que aquí trataremos, en este caso ante toda la corte, con el rey a la cabeza, corría el peligro de precipitarse en el exceso de adulación hacia el personaje encarecido, caer en la demasiada afectación o, lo que era muy grave, torcer el sentido de la Sagrada Escritura que podría determinar ser objeto de las miras de la Inquisición, al desviarse de la ortodoxia.

Entre las muchas honras que predicó Florencia a personajes de la monarquía, destacan especialmente las dedicadas a la emperatriz doña María, de $1603^{14}$, las que trataremos aquí en honor de la reina doña Margarita de Austria en su Sermón primero [Madrid, san Jerónimo el Real, y en Santa María, 1611], y las del rey Felipe III, también en san Jerónimo el Real, en $1621^{15}$. Aunque las que le catapultaron a la fama fueron las predicadas por el alma del arzobispo de Toledo don García de Loaysa, en 1599, que había sido consejero de Felipe II, ayo del príncipe Felipe, el futuro rey, y de Francisco de Quevedo ${ }^{16}$.

En esta aportación, estudiaremos estas primeras honras predicadas en san Jerónimo el Real a partir del análisis del contexto en el que se producen y, particularmente, en el marco del aulicismo, que fue tan característico de este destacado predicador real, distinguiendo los elementos estructurales que lo configuran, como son: el título, la dedicatoria, el tema del sermón, para centrar nuestra interpretación en el cuerpo que desarrolla la imagen de la reina fallecida como un ser sacralizado.

\section{El sermón: título y contexto}

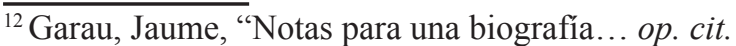

${ }^{13}$ Citado por Herrero, Félix, La oratoria sagrada en los siglos ... op. cit., p. 449.

${ }^{14}$ Servera, José, "Jerónimo de Florencia, predicador de honras... op. cit.

${ }^{15}$ Garau, Jaume, "Jerónimo de Florencia y su sermón a las honras fúnebres... op. cit.

${ }^{16}$ Garau, Jaume, "Notas para una biografía... op. cit., p. 111.
} 
El Sermón que predicó a la majestad del Rey don Felipe III, nuestro Señor, [...] en las honras que su majestad hizo a la Serenísima Reina doña Margarita, su mujer, que es en gloria, en san Jerónimo el Real de Madrid, a 18 de noviembre de 1611 años. (Madrid, Juan de la Cuesta, 1611). ${ }^{17}$

El 3 de octubre de 1611 moría la reina Margarita de Austria de sobreparto. Poco más de un mes después, el 18 de noviembre, predicaba sus honras, en san Jerónimo el Real de Madrid, como refleja el título de la edición que manejamos, Jerónimo de Florencia ante el rey Felipe III y toda la corte. Hacía pocos años que se había producido el acercamiento de nuestro predicador al poder, aproximación que podemos comprobar en su nombramiento de predicador real en marzo 1609, como prueba el expediente que localizamos en el Archivo General de Palacio ${ }^{18}$, dotado con sustanciosos gajes. El padre Florencia fue el primer jesuita en iniciar el aulicismo de su orden en España, fruto, en buena medida, de sus excelentes relaciones con la aristocracia, como ya hemos visto, y, en particular, por su buena amistad con la reina Margarita a quien oficiará las honras. Gracias a esta relación con la reina, experimentará un destacado ascenso en la Corte, al que no fue ajeno su importante nombramiento de predicador del rey, como hemos visto, y, también relacionado con este hecho biográfico, su adscripción al grupo antilermista, como al que ya nos hemos referido, según refiere Fernando Negredo:

\footnotetext{
Muy pronto contó con la simpatía de la reina Margarita y por tanto fue tenido como elemento contrario al grupo lermista, máxime cuando era tan recibido en el convento de las Descalzas, donde se rumoreaba que se reunía, en torno a Sor Margarita de la Cruz, el gran grupo opositor al valido; pero aún así, durante el tiempo de su ascenso consiguió mantenerse en la corte sin granjearse demasiados enemigos y por tanto, sobrevivir ${ }^{19}$.
}

Juan Eusebio Nieremberg abunda en detalles de esa amistad con la reina Margarita de Austria de la que afirma que:

\footnotetext{
le tuvo notable amor, y una estimación extraordinaria de su santidad, religión y prudencia: Comunicaba con él todas las cosas de su alma y hacía grandes demostraciones significadoras de la estima grande que de él tenía ${ }^{20}$.
}

En esa imagen impecable de la Compañía de Jesús que traza Nieremberg, en su obra Honor del Gran Patriarca que citamos, atribuye la anécdota del retraso de Florencia a una cita

\footnotetext{
${ }^{17}$ Dada la trascendencia del personaje en cuestión y la importancia de estas honras, este sermón tuvo mucha difusión en las prensas. Para una mayor información puede consultarse el excelente Catálogo Colectivo del Patrimonio Bibliográfico Español, «http://www.mcu.es/ccpb/ccpb-esp.html», entre otras bases de datos. En la transcripción de títulos y de pasajes regularizamos la ortografía siguiendo las normas del español actual, aunque respetando las variantes que tengan trascendencia fonética.

${ }^{18}$ Garau, Jaume, "Notas para una biografía... op. cit., p. 111.

${ }^{19}$ Negredo, Fernando, Política e Iglesia. Los predicadores de Felipe IV... op. cit., p. 34.

${ }^{20}$ Nieremberg, Juan Eusebio, Honor del Gran Patriarca san Ignacio de Loyola, fundador de la Compañia de Jesús en que se propone su vida y la de su discípulo el Apóstol de las Indias san Francisco Javier, Madrid, 1649, p. 630.
} 
con la reina y que cuando esta supo que don Jerónimo acababa de llegar dijo "Sea en buena hora, dejemos esto, que por un rato de Florencia todo se ha de dejar"21.

Como en todo sermón fúnebre, y particularmente en el caso de un personaje poderoso, la muerte aparece arropada de una especial ejemplaridad que contrasta frente a la del hombre común. Como decía un contemporáneo de Florencia, el padre Agustín de Castro:

Común es la ley de morir; pero con todo esto causa mayor desengaño ver morir al rico, al poderoso, al Príncipe, que no al hombre plebeyo; pues se conoce que ni la riqueza, ni el poder pueden hacer estorbo al golpe incontrastable de la muerte ${ }^{22}$.

Dos son los protagonistas de este tipo de sermones: el hecho inexorable de la muerte, y las consideraciones en torno a ella, y el difunto que, en este caso, se constituye en una figura de ejemplaridad, como hemos dicho. De ahí que el texto presente un carácter dual en el que el predicador se extiende, primero, en reflexiones tópicas sobre la vida y la muerte, autorizadas mediante la doctrina; $y$, en segundo lugar, desarrolla la que podríamos considerar la parte panegírica de la pieza oratoria, en la que se glosan los hechos y virtudes que adornaron la vida del fallecido, en nuestro caso, la reina Margarita de Austria, al punto de presentar su existencia terrenal como ejemplo que sobrepuja al resto de los mortales. En consecuencia, al tiempo que se exalta a la persona difunta se enaltece a la institución monárquica que esta representa ${ }^{23}$.

\subsection{El sermón en el marco del aulicismo de la Compañía}

No debemos olvidar, por otra parte, que, pese a la prohibición explícita, que tenían los jesuitas de participar en la política, siempre y cuando esa participación no fuera necesaria para la defensa del catolicismo, normalmente tomaban partido dada la imbricación entre el trono y el altar característico de la Monarquía Hispánica. Florencia es, como vamos viendo, un jesuita especialmente distinguido por su implicación en la esfera del poder de la monarquía, como muy bien documenta Lozano Navarro, al transcribir parte de una carta que le dirigió el general Vitelleschi, desde Roma, en 1621, tiempo en el que la influencia de Jerónimo de Florencia en la Corte era destacada. En esta carta, Vitelleschi manifestaba que:

[...] no es de nuestra profesión entremeternos en cosas tocantes a razón de estado, pero cuando estas coyuntan con la conservación de la fe, con el bien espiritual de nuestros prójimos y gloria de Nuestro Señor, es necesario que

\footnotetext{
${ }^{21}$ Ibídem, p. 630 .

${ }^{22}$ Citado por Herrero Salgado, Félix, La oratoria sagrada en los siglos XVI y XVII... op. cit., p. 450.

${ }^{23} \mathrm{La}$ tradición del sermón funeral, analizado desde la perspectiva del género en el que se inserta, se inspira en los grandes discursos panegíricos de la Antigüedad, de manera que, en la historia de la Iglesia, los dedicados a los santos y reyes sustituyen a los de los emperadores romanos, aunque a diferencia de estos, los cristianos se distinguen por su carácter exhortativo, en el sentido de presentar ante los fieles las virtudes que distinguían al fallecido, al que se toma como ejemplo a seguir, como hemos dicho, con el propósito de obtener, más allá de esta vida, el premio prometido por Dios.
} 
correspondamos a nuestra obligación haciendo el deber y ayudando en todo lo que pudiéramos a un negocio de tanto servicio de la Divina Majestad [...]. ${ }^{24}$

Ciertamente en una sociedad sacralizada como aquella es difícil imaginar qué asuntos podían sustraerse a la influencia de la religión, singularmente en aquellos vinculados a personalidades relevantes de la Monarquía y, en particular, como muy bien ha resaltado Lozano Navarro, cuando aquellas "eran soberanas o mujeres pertenecientes a estirpes principescas" 25 . Tanto fue así que, a través de esas relaciones la Compañía fue conocida, ampliando su esfera de influencia de la que la predicación de estas honras no fue una excepción.

Tales antecedentes justifican sobradamente que se le encargase a Jerónimo de Florencia la predicación de las honras oficiales de la reina de España, en la iglesia de san Jerónimo el Real de Madrid el 18 de noviembre de 1611, como así sucedió tras oficiar la misa por su alma, según atestigua el cronista Diego de Guzmán al escribir que:

\begin{abstract}
Acabada la misa, predicó el padre Jerónimo de Florencia, de la Compañía de Jesús y predicador de su Majestad, un docto sermón lleno de alabanzas de la Reina, nuestra señora. Sacó hartas lágrimas del auditorio que estaba tierno y devoto. $^{26}$
\end{abstract}

Este sermón podemos considerarlo representativo del estilo clasicista del que hizo gala durante su carrera, en la línea de los grandes predicadores del Quinientos y en contraste con los autores, ya calificados de "cultos" en su tiempo, a los que denuncia el abuso de las "palabras afeitadas", en el prólogo de su Marial (1625), y entre los que cabe imaginar una alusión a su competidor fray Hortensio Paravicino, distinguido por el cultivo de este estilo.

\title{
1.2.1. Dedicatoria al Rey Nuestro Señor
}

Comienza la dedicatoria con una referencia a las palabras de san Jerónimo a santa Paula con motivo de la muerte de su hija Blesila, con quien establecerá un paralelismo según el cual el predicador quiere asemejarse a san Jerónimo, y la fallecida reina Margarita a Blesila.

Sigue en esta dedicatoria la tópica captatio benevolentiae. El predicador se muestra agradecido a la reina fallecida "en reconocimiento de tantas y tan grandes mercedes como a nuestra sagrada religión en todas ocasiones su Majestad hacía, obligando a todos los de ella, hasta el menor que soy yo, a ser sus perpetuos capellanes" (f. 162v).

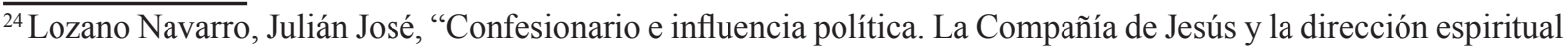
de princesas y soberanas durante el Barroco”, en José Martínez Millán, Henar Pizarro Lorente y Esther Jiménez Pablo, Los jesuitas: religión, política y educación (siglos XVI-XVIII), vol. 1, Universidad Pontificia de Comillas, Madrid, 2013, p. 183.

${ }^{25}$ Ibidem, p. 184.

${ }^{26}$ Reina Católica. Vida y muerte de doña Margarita de Austria, reina de España, Madrid, Guzmán, Diego de, 1617, 259.
} 
1.2.2. Tema del sermón: Libro de la Sabiduría, 7, 5-10

La cita bíblica que encabezaba todo sermón, conocida como el tema, era tomada de un pasaje de la Biblia Vulgata. Es la siguiente:

5 nemo ex regibus aliud habuit nativitatis initium.

6 unus ergo introitus est omnibus ad vitam et similis exitus

7 propter hoc optavi et datus est mihi sensus et invocavi et venit in me spiritus sapientiae

8 et praeposui illam regnis et sedibus et divitias nihil esse duxi in conparatione illius

9 nec conparavi illi lapidem pretiosum quoniam omne aurum in conparatione illius harena est exigua et tamquam lutum aestimabitur argentum in conspectu illius

10 super salutem et speciem dilexi illam et proposui pro luce habere illam quoniam inextinguibile est lumen illius.

Que, en traducción castellana de Felipe Scio, reza así:

${ }^{5}$ Porque ninguno de los reyes tuvo principio de nacer.

${ }^{6} \mathrm{Y}$ así una misma es para todos la entrada a la vida, y semejante la salida.

${ }^{7}$ Por esto deseé, y me fue dada inteligencia, e invoqué, y vino en mí el espíritu de sabiduría:

${ }^{8} \mathrm{Y}$ apreciela más que los reinos y tronos, y juzgué que las riquezas nada son en comparación de ella:

${ }^{9} \mathrm{Ni}$ cotejé con ella las piedras preciosas: porque todo el oro en su comparación es una arena menuda, y la plata será tenida como barro delante de ella.

${ }^{10}$ Amela más que la salud y la hermosura, y propuse tenerla por luz: porque es inextinguible su resplandor (Libro de la Sabiduría, 7, 5-10). ${ }^{27}$

\subsubsection{Cuerpo del sermón}

Comienza su exposición Florencia realizando una paráfrasis del contenido del tema de estas honras en las que se valora la virtud y, concretamente, el "espíritu de sabiduría", tal cual reza la cita del Testamento Viejo sobre el que va a articular todo su sermón en honor de la fallecida reina Margarita de Austria.

\footnotetext{
${ }^{27}$ La Biblia Vulgata latina, traducida en español, y anotada conforme al sentido de los Santos Padres y expósitores católicos, traducción de Felipe Scio, Valencia, Joseph y Thomas de Orga, MDCCXCIII.
} 
Argumenta, pues, que pese al privilegio del que gozó Salomón, en haber sido rey, este hecho no invalida, en modo alguno, la universalidad del nacimiento como el resto de los mortales y el sino que supone la muerte al igual que todos ellos. Sin embargo, y frente a todos los honores y riquezas del mundo, la sabiduría y la virtud resplandecen sobremanera sobre todo.

Justifica así el tema elegido para su sermón en la realeza a la que pertenecía Salomón, como la reina Margarita, y el modo, o "instrucción y orden para consolar al rey nuestro señor" que, según manifiesta, se lo proporcionó el papa Gregorio $\left(\mathrm{v} 1 \mathrm{v}^{\mathrm{o}}\right)$, al tiempo que advierte que para "consolar al afligido ha de [...] vestirse de su dolor".

Además, aprovechando una breve reflexión sobre su experiencia en la predicación de honras, recurre a la mención de lugares tópicos que refuerzan sobremanera el carácter exhortativo y suasorio que es característico de la oratoria sagrada, y dice así:

\footnotetext{
En muchas ocasiones de honras que he predicado heme pasado siempre de parte de la muerte, como un pobre hombre y mortal que ha de parar en sus manos. He hecho sus partes, predicando los grandes provechos que acarrea con su memoria en vida y, en el remate de ella, con su presencia. En vida, moderando codicias, enfrenando envidias y templando tristezas vanas y, al fin de la vida, rematando con tantas penalidades y miserias della que por esto san Ambrosio llamó a la muerte [...] la raya de nuestras penas. (f. 2)
}

Argumenta, retóricamente, que estando tan afectado por la muerte de la reina necesita acudir a los Sagrados Doctores para que inspiren "las comas y ápices deste sermón" (f. 2), de modo y manera que el texto predicado adquiera la necesaria "Autoridad" que reclama la explicación de la palabra divina.

Y entre estos, recurrió primero a san Basilio y después a Gregorio Niseno del que toma un lugar, en relación a la muerte de la emperatriz Placilla en el que se dice que:

\footnotetext{
cuando mueren personas que son columnas de la Iglesia son calamidades estas más dignas de lágrimas que las guerras, pestes, hambres, terremotos, aberturas de tierra y inundaciones del mar. Porque esas calamidades, si alcanzan a unas partes de los reinos, otros quedan libres, pero la falta de una columna de la Iglesia es común calamidad y llaga de toda ella. (f. 2)
}

\subsection{La Reina, ser sacralizado}

Ya hemos visto la particular relación de amistad que tenía Jerónimo de Florencia con la reina Margarita de Austria y la importancia que podía representar esta amistad nada menos que de la soberana, en vistas al afianzamiento de la Compañía y sus relaciones con la Corona. De ahí que la figura biográfica de la reina aparezca retratada, tanto por la pluma como el pincel, como una suerte de trasunto menor de la Virgen María. De ahí que Lozano Navarro sostenga que: 
[...] la vida de la esposa de Felipe III irá siempre acompañada de una cierta aureola de santidad. Algo que explica, por lo pronto, que esta reina se constituya en un paradigma dentro del proceso de construcción icónica que culminó con la sacralización de la imagen de las soberanas del Barroco. Una dinámica que llegaba a transformarlas en trasuntos menores de la Virgen María. Hasta el extremo de que, en el caso de Margarita de Austria, Pantoja de la Cruz la retrate a lo divino, prestando sus rasgos a la Madre de Dios. ${ }^{28}$

La reina Margarita, pues, se presentará en nuestro sermón como un modelo arquetípico de reina ideal, en cuya figura se conjuga la grandeza de una reina con la sencillez y religiosidad de una monja.

Se anuncia su figura como la de un ser sacralizado adornado por las más hermosas virtudes que conforman la etopeya de la reina fallecida: era una dulce compañía para el rey; una amorosa madre para sus hijos; una piadosa reina para sus vasallos y, la cuarta razón y no menos importante, "una fuerte y firme columna" para la Iglesia universal, aspecto este último que repetirá en diversas ocasiones a lo largo del sermón.

Por esta razón, argumenta que el sermón que va a predicar debe estar inspirado por personas de una gran calidad humana y espiritual: “el tema me lo habrá dado un rey; la salutación, un papa; el sermón los cuatro doctores de la Iglesia que, en honras de tal reina, no es razón que hablen personas de menor autoridad" (f. 3).

De ahí que, consecuentemente y de acuerdo con lo que podríamos denominar una "jerarquía de autoridad" que se proyecta en diversas esferas de poder y estados:

Llore, pues, por el rey nuestro Señor el mayor dotor de la Iglesia que es Jerónimo, escribiendo en otra ocasión semejante a la nuestra a Panaquio sobre la muerte de Paulina, su mujer. Por sus altezas, llore Agustino, llorando la muerte de su madre santa Mónica. Por los vasallos, llore Ambrosio, llorando la falta que hizo a los suyos el emperador Valentiniano, muriendo mozo. Por la Iglesia universal, el universal pastor de ella san Gregorio, llorando la falta que en ella hacía un gran perlado, llamado Euterio. (f.3)

En apoyo de su texto, trae a colación lugares tomados de las cartas de san Jerónimo, en cuyo templo nos recuerda, se celebran estas honras. Y, a partir de la epístola en la que el doctor de la Iglesia glosa la muerte de Paulina, Florencia encarece que en la reina Margarita no faltó la "misericordia, castidad, santidad, inocencia de vida y todas las virtudes que, en la muerte de una sola persona" (f. 3).

Como la reina murió en plena juventud de sobreparto, este hecho luctuoso lo presenta Florencia mediante el recurso, tópico, por otra parte, del recurso a la flor de la rosa que se marchita tan fuera de tiempo que no permite que se cumpla $-\mathrm{y}$ también al sentido etimológico

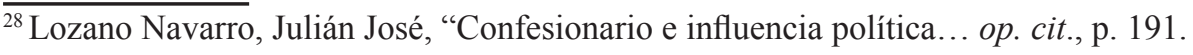


que presenta su nombre como "perla"-, como reinado breve que fue el de Margarita, parafraseando a san Jerónimo a la muerte de Paulina, sigue:

\begin{abstract}
¿A quién no lastimara el ver una grande y preciosa margarita perder su lustre y resplandor y deshacerse en polvos? Esto dice san Jerónimo. Y, si en una rosa donde es impropio el parto, enternece el verle mal logrado, ¿cuánta mayor ternura y lástima causara ver tras un parto tan dichoso un tan infeliz sobreparto que acabó con una reina de España, tan querida y amada de todos? ¿Quién no llorara viendo desecha en polvos a la que tenía deudo en el nombre con las margaritas y, en el lustre y valor, a todas ellas incomparable exceso? (f. $3 \mathrm{v}^{0}$ )
\end{abstract}

Establece Florencia un paralelismo entre las honras que predicó san Ambrosio, el gran padre de la Iglesia de Occidente, con motivo de la temprana muerte del emperador Valentiniano II (371-392), de quien afirma, como así fue: “que murió mozo" (f. $3 \mathrm{v}^{\circ}$ ) y, al igual que aquel en la predicación de san Ambrosio, se perdió entonces un emperador como ahora una gran reina en quien resalta, y obsérvese la paradoja: "sus tiernos años y sus maduros consejos" (f. 4) A lo que continúa:

\footnotetext{
Porque tenía su majestad, siendo tan moza, unos pensamientos tan ancianos, unos designios tan santos, unos deseos de el bien común tan encendidos, que parecía más su celo de ancianos papas y pontífices de la Iglesia, que no de una tierna reina. Y así, pues, toda ella ha perdido una firme columna. (f. 4)
}

En un sermón de honras, se impone la reflexión sobre la muerte y lo que esta representa en la vida del cristiano. El hecho biográfico de fallecer la reina de sobreparto aúna los conceptos, aparentemente opuestos, de muerte y vida: de modo y manera que, en la relación de sucesos que se refiere a lo largo del discurso sagrado, al nacimiento de una nueva criatura le sigue la muerte de la madre. Aunque para el creyente esta muerte comporta el nacimiento de la reina hacia la vida auténtica de la eternidad.

De gran efectividad son, a lo largo de todo el sermón, las invocaciones que contribuyen poderosamente a reforzar la idea de una muerte como sino igualador de todos los hombres en la coronación, como se presenta en este caso, de una vida virtuosa y ejemplar que trasciende, como ya se ha dicho en el sermón, el ámbito de la vida familiar en la Corte para iluminar a todo el reino.

Los poderosos apóstrofes con que Jerónimo de Florencia se dirige a la muerte revelan la capacidad que esta figura patética tiene en el destinatario de su predicación, primero toda la Corte con el rey a la cabeza; para, desde el momento de la difusión impresa del texto, abarcar a la totalidad de sus lectores. Así, al invocar a la muerte, Florencia recurre a una figura que cumple la función, fundamental en el género de la oratoria, de mover el ánimo del oyente, al tiempo que, en virtud de la figura, se pretende que se retenga el contenido moral que persigue el orador sagrado: 
Quejome, pues de ti, ¡Oh muerte cruel, fiera, traidora, hija de padre traidor, que es el pecado! Con razón te pintó la Antigüedad sin entrañas, porque no las tienes para compadecerte de nadie. ¡Qué crimen de laesae maiestatis has cometido acometiendo una reina! Por ley se libran de ti con sola la vista de los reyes los que a ti están sentenciados, ¡Y a una reina no le valió el serlo para librarse de ti! Cuando embistes con una persona pobre, enferma, vieja, sin crédito ni honra, entonces pareces que andas algo piadosa. [...] Pero en el caso presente, ni acataste tanta majestad, ni te apiadaste de tan florida edad, ni te compadeciste de tan gallarda y entera salud. (f. $4 \mathrm{v}$ )

Es difícil desligar la enseñanza que comporta la predicación del ropaje retórico del que el mensaje cristiano aparece revestido. La muerte, como dice Florencia, es "traidora, hija del padre traidor, que es el pecado" — como acabamos de leer — ya que así se explicita en el relato de Creación del Génesis: el hombre peca, desobedece a Dios y cae en el pecado instigado por el demonio. Pierde el Paraíso, del que es expulsado, y con ello conoce la muerte de la mano del tiempo que surge en aquel momento, junto al dolor del que estaba ausente en el estado edénico.

Las invocaciones a la muerte cruel se suceden en los primeros momentos del sermón. La muerte no se apiadó ni de la reina ni del rey. Tampoco de los hijos, presentados como "tantos, tan lindos y tan tiernos con quien fuiste tan cruel quitándoles tal madre, y en una edad en la que les hiciese falta su crianza y de tanto bien como perdieron apenas les quedase aun memoria" (f. $4 \mathrm{v})$.

La ausencia de esta pérdida es mayor si cabe en el caso del infante Alfonso ${ }^{29}$, muerto a los pocos meses de nacer (17 de septiembre de 1612) y por cuyo parto muere la reina, sin haber llegado a cumplir un año, a quien supone el predicador real el tener, por culpa de la muerte de su madre, "atravesada aquella espina de haber sido ocasión de tanto daño. Aunque la verdad, al ser tan tierno, como si tuviera discreción, tuvo piedad de su madre y no la mató al salir de sus entrañas, sino tú, ¡Oh fiera muerte!, después de haber él salido” (f. 5).

Se establece, a partir de aquí, un "razonamiento fingido", típico de la predicación sagrada, según el fray Luis de Granada de la Retórica Eclesiástica ${ }^{30}$, por cuyo procedimiento participa la propia muerte en la defensa de sus acciones a partir de su universalidad para con todos los hombres. Habla la muerte, por boca de nuestro predicador en estilo indirecto:

Como los reyes no tuvieron otra manera de entrar en este mundo, sino llorando como todos, no han de tener otra de salir dél sino muriendo como todos. Yo no soy tan traidora (aunque tenía bien a quien parecerlo, que es mi padre el pecado) porque después que este entró y reinó en el mundo todos los hombres,

\footnotetext{
${ }^{29}$ Sobre este infante, es interesante el estudio de Cobo Delgado, Gemma, "Retratos infantiles en el reinado de Felipe III y Margarita de Austria: entre el afecto y la política", en Anuario del Departamento de Historia y Teoría del Arte, 25 (2013), pp. 23-42.

30 "Hay también una figura que se llama Sermocinatio, esto es, Razonamiento fingido, que se cuenta entre las descripciones de personas, y no sé yo si hay cosa que más pertenezca al oficio de predicador que esta; no solo para el modo de amplificar sino también para otros fines", Granada, Luis de, Los seis libros de la Retórica Eclesiástica o de la manera de predicar, Madrid, Biblioteca de Autores Españoles, 11, 1944, p. 5.
} 
aunque sean reyes, libremente se le avasallaron. Y como yo soy hija legítima y heredera suya $[\ldots]$ heredé el señorío de todos esos vasallos. Y así yo, aun cuando me llevo a los reyes, no mato reyes, sino vasallos míos, y cuando los acometo no cometo crimen laesa maiestatis. (f. 5)

El imperio de la muerte, de la crueldad que lleva aparejada en el caso de la muerte de una reina joven en la flor de su edad, está sujeta al gobierno de la Providencia. Desde el momento de la Redención en el que Cristo se sacrifica por el hombre en el altar de la Cruz, Dios es el señor de la vida y de la muerte, como manifiesta por boca del predicador:

Yo — dice la muerte en estilo indirecto- desde que Dios murió en la Cruz quedé por su prisionera [...] tiéneme encerrada, no entro ni salgo sino por su orden; no mando, sino obedezco; no trazo, sino ejecuto. (ff. 5-5v)

La muerte de la reina se presenta como un hecho luctuoso que fundamenta la esperanza en su justa salvación, en compañía de los salvos en la eternidad gozosa del cielo prometido. El nombre de la reina, Margarita, con las posibilidades expresivas y semánticas que proporciona en su sentido culto, como perla preciosa, permite al predicador extenderse en consideraciones que aúnan el sentido de la voz, con matices figurados que ineludiblemente se asocian con el valor material de la perla y su trascendencia, en este caso espiritual e inconmensurable, que le otorga el haber rendido su alma a Dios en plena juventud y después de una intensa dedicación a la piedad, expresión sincera de la virtud cristiana que adornó su breve vida:

\footnotetext{
en medio de las ricas piedras y preciosas margaritas, sola la virtud y buena vida es la que tiene valor y lustre que jamás se pierde. Esta es la que tiene precio, y en su comparación todos los demás bienes temporales no son nada; y así quien los deja por ir a gozar de los eternos, debidos a las heroicas virtudes y santa vida, no pierde sino gana, y con grandes ventajas se mejora. Y no son tan preciosas en los ojos de los hombres las hermosas y ricas margaritas cuanto lo es la muerte de los justos en los ojos del Señor.

El consuelo, pues, que hemos de tener en la pérdida de nuestra serenísima reina y preciosa Margarita es que en sí, ni para con Dios, ni para con nosotros ha bajado de precio sino subido y adquirido mayor lustre y resplandor (f. $6)$.
}

Florencia glosa los provechos de la muerte para el creyente, en un texto estructurado sobre la tópica figura de la antítesis que tal oposición supone, y que se constituye en el correlato estilístico del antagonismo entre el vivir y el morir tantas veces invocado en la estética barroca, dada su inclinación por la conjunción de contrarios en un mismo sujeto. Como escribía un epígono de Góngora, Antonio Gual (1594-1655), en el prólogo a un romance que escribió sobre la muerte: 
Todos aman la vida, que tuvo por ascendiente la muerte, por compañía el desfallecimiento, y por sucesor el no ser: y temen y aun aborrecen la muerte, que procedió de la vida, tiene por consorte la eternidad, y por descendencia la perpetuidad del vivir. ${ }^{31}$

Y entre estos provechos que supone la muerte está el desengaño que comporta la muerte de la reina en estas honras:

De manera que por la parte del alma no hay que llorarla, sino envidiarla, pues está más lúcida y resplandeciente que antes. Y, por la otra parte, que es la del cuerpo, aun ha crecido en luz y resplandor para nosotros pues desde su ataúd nos arroja rayos tan poderosos de verdadero desengaño. (f. $6 \mathrm{v}$ )

Y en esta presentación de virtudes, sigue la línea antes señalada de presentarnos a una reina distinguida por la piedad, a la que no fue ajeno su esposo Felipe III, tantas veces acusado de abandonar los negocios de la monarquía en sus desvelos por estar pendiente de su alma, como revela su epíteto de "El Piadoso" con el que ha pasado a la historia.

Su celo religioso se encarece en la línea de cuidar "la verdad oficial" que se espera oír:

De aquí le nacía — dice Florencia — el gustar mucho de oír predicar este punto de la eternidad de gozos o tormentos. De aquí un temor entrañable y propósito firme de nunca hacer un pecado mortal, aunque le costase la vida. De aquí el estar tan obediente a su confesor como si fuera una religiosa novicia (f. 7).

Y en esta presentación de las virtudes por las que resplandecía Margarita de Austria, destaca Florencia su amor por la justicia y su preocupación por el buen gobierno de los reinos de España:

Murió pues, la que era amparo de la justicia. [...] Una persona muy religiosa le oyó decir varias veces, con lágrimas en los ojos, que ordinariamente ofrecía a Dios nuestro Señor, la vida y el morir en la flor de su edad en razón que el gobierno de todos los reinos de España fuese cual conviene, y que en todo se guardase justicia, a la cual era su majestad tan inclinada (f. 7).

Amante de los pobres, empeñada en favorecer las obras de la Iglesia en lo tocante a patrocinar nuevos edificios, dotar nuevas obras pías, etc. En este sentido, el desarrollo del sermón sigue un esquema parecido al de la letanía por el que el predicador menciona un texto en latín como, por ejemplo, "Protectora de los pobres" traducimos, entre otros propios de la letanía que se va extendiendo, cual rezo mariano, a lo largo de la parte final de las honras.

De este modo, la presentación icónica de Margarita de Austria, como trasunto de la Virgen, propia de la época como hemos visto, en cierto modo se reproduce en el modo retórico

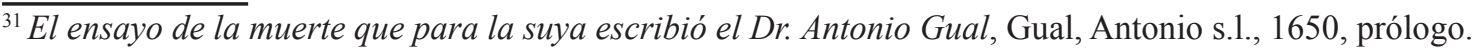


del sermón en la medida en que si en el rezado de la letanía se persigue el perpetuar en el tiempo y el espacio las virtudes que son propias de la Madre Dios, en el texto a partir del remedo de esta letanía que comporta la relación de virtudes que adornan a la reina, se perpetúa, también en el tiempo y el espacio, la explicación de esta misma idea mediante el recurso a la amplificatio que es tan propio de la oratoria sagrada.

\section{Final}

Hemos intentado presentar en estas notas sobre las honras de Jerónimo de Florencia a la reina Margarita de Austria, en su Sermón primero, cómo un importante predicador de nuestro Siglo de Oro aborda la muerte por sobreparto de una reina de España, a partir de los recursos retóricos, y tópicos que la configuran, desde la perspectiva de su imagen oficial, como una figura política sacralizada, en consonancia con el sentido a la vez sacralizado de la monarquía en el Antiguo Régimen y como una vía más para comprender su importante figura, desde la perspectiva de un destacado predicador real muy cercano a los círculos del poder. 